\title{
Replaying Today's Wars? A Study of the Conceptualization of Post-1989 Conflict in Digital "War" Games
}

\author{
Pieter Van den Heede ${ }^{1}$ (D) Kees Ribbens $^{1,2} \cdot$ Jeroen Jansz $^{3}$
}

Published online: 6 September 2017

(C) The Author(s) 2017. This article is an open access publication

\begin{abstract}
Commercial "war" games in a post-1989 setting are popular among a large audience. They offer players an enjoyable gameplay experience, while also referring to contemporary "war" scenarios. As such, they have been studied in several ways, e.g., concerning the "realistic" nature of how they depict warfare. However, little is still known about the way in which the notion of "war" is conceptualized in these games. To fill this gap, this article offers a systematic analysis of the narrative content of 15 popular "war" games set after 1989, as well as their promotional descriptions, as these provide insight into how publishers respond to the interests of players. This is done based on the conceptual framework of conflict/war offered by the Uppsala Conflict Data Program (UCDP).
\end{abstract}

Keywords Digital games $\cdot$ Post-1989 $\cdot$ War $\cdot$ Conflict $\cdot$ UCDP

Pieter Van den Heede

vandenheede@eshcc.eur.nl

Kees Ribbens

k.ribbens@niod.knaw.nl

Jeroen Jansz

jansz@eshcc.eur.nl

1 Department of History, Erasmus University Rotterdam, Burgemeester Oudlaan 50, 3062

PA Rotterdam, The Netherlands

2 NIOD Institute for War, Holocaust and Genocide Studies, Herengracht 380, 1016 CJ Amsterdam, The Netherlands

3 Department of Media \& Communication, Erasmus University Rotterdam, Burgemeester Oudlaan 50, 3062 PA Rotterdam, The Netherlands 


\section{Introduction}

On May 1, 2016, the American game development studio Infinity Ward, the creator of the Call of Duty: Modern Warfare games, released a promotional video in which employees reflected on what they liked most about the games, and what they wanted to bring to the new installment of the series, Call of Duty: Infinite Warfare (Infinity Ward 2016). They described Modern Warfare as a "fast," "super-realistic," "high-intensity action roller coaster," and stated:

\section{"You're being transported into a warzone, and that's an experience no other game quite matches."}

"It was a playable 'Black Hawk Down', but it was also a playable CNN."

These characterizations correspond to what Payne describes as a double premise of the game Call of Duty: Modern Warfare. It seeks to offer players an enjoyable and intense gameplay experience, while portraying a set of "authentic theatres of war, both historic and those "ripped from today's headlines'” (Payne 2012, p. 310). As such, this premise has been subjected to extensive criticism, as several scholars have described how games like Call of Duty offer very selective depictions of war and military conduct, in which negative aspects of combat are filtered out. At the same time, it raises new questions, in particular about the way in which the notion of "war" itself is conceptualized in these games. What do the developers mean when they talk about a "warzone," and to what extent do the conflicts as depicted in the games offer a reflection of the nature of contemporary conflict, which has changed significantly since the end of the "age of total war" in 1945 (Black 2010) and the end of the Cold War in 1989 in particular? As games like Call of Duty are meant to entertain and thus prioritize enjoyability, they assumedly offer depictions of war that avoid specific types of conflict in specific regions. At the same time, as games have become increasingly popular over the past decade and thus can have a significant impact on how players think about the nature of post-1989 warfare, further analysis into the representation of contemporary conflict in games is required. Therefore, this article tries to answer the following question: how is the notion of "war" conceptualized in popular digital entertainment games, and how does this compare to contemporary conflicts worldwide? We aim to answer this question by first looking at the promotional descriptions of 15 popular game series about "war" in a post-1989 setting, as they potentially contain information about the conflicts depicted in the games, while at the same time providing insight into how the game publishers respond to the interests of the players. Second, we aim to study the types of conflicts depicted in the games through narrative content. Here, we use the conceptual framework of conflict and war as provided by the Uppsala Conflict Data Program (UCDP) as a point of reference, as it allows us to make a comparison with the types of conflicts that have occurred worldwide since 1989, and gain insight into the extent to which these developments are visible within the studied "war" games. In particular, we focus on the locations in which the games take place, the nature of the armed factions that are depicted (whether they are government-based or not) and the conflicts in which they are involved, the extent to which the factions commit violence against civilians, and whether the games portray real-life or fictional conflicts. Furthermore, we will identify which of the factions can be characterized as protagonists and antagonists, as it shows which perspective is presented to the players.

In the following paragraphs, first an overview of the existing research on the representation of "war" in digital games will be given, after which the conceptual framework of UCDP and 
some general tendencies in the development of conflict since 1945/1989 will be discussed. Next, a comprehensive overview of the applied methodology will be given, as well as an overview of the research results.

\section{Literature Review}

In recent years, digital entertainment games about conflict/war have received a significant amount of scholarly attention. Especially military-themed games have been studied, as they were identified as a product of a "military-entertainment complex," that is, the close collaboration between the military, private technology firms, and the entertainment industry in the USA in particular (Dyer-Witheford and De Peuter 2009; Huntemann and Payne 2010). This collaboration came about during the second half of the 1980s, when the American military underwent important changes (Herz 1997). It saw a shift in its strategic concerns towards international terrorism and small-scale warfare, while a great emphasis was put on the use of simulations and information communication technologies to reduce training costs and the number of casualties on the battlefield. This effort coincided with the breakthrough of 3D imaging technologies within the gaming industry and the rapid increase of computational power during the early 1990s (Malliet and de Meyer 2005). It led the military to abandon its costly "historical reliance on contracting with dedicated segments of the US technology and industrial base" (Lenoir 2002, p. 14) and seek an active collaboration with private interactive companies to create digital games and simulation applications, to the mutual benefit of both sectors (Huntemann and Payne 2010; Kline et al. 2005).

As such, the military-themed games that were produced in this context have been studied in various ways, since they, as a popular form of "militainment," potentially reinforce the militarization of cultural space, by letting citizen-consumers actively partake in military conduct (Stahl 2006). In that respect, especially the genre of the first and third person shooter (FPS/TPS) game has been studied, and the extent to which they offer "realistic" depictions of war. Through a quantitative content analysis of military-themed FPS games, Breuer et al. (2012) identified three types of "realism" that could be found therein, based on the typologies offered by Galloway (2004) and Busselle and Bilandzic (2008): representational realism, which refers to aspects of the audiovisual presentation such as graphics and sounds; behavioral realism, which is related to player interactions and the effects they have in the game world; and narrative realism, which refers to narrative elements such as characters and settings, and the extent to which they correspond to real-world events. Following this, they argued that military FPS games tend to prioritize representational realism over other aspects, describing it as "what game developers and publishers usually have in mind when they market their products as 'realistic'" (Breuer et al. 2012, p. 218). This is partly contradicted by Payne, who also stresses the importance of narrative and behavioral elements (Payne 2012), and Halter (2006) and Mirrlees (2009), who, in their analysis of the "modalities of simulated realism" of war games, additionally highlight aspects of subjective realism, or the ability for players to take up a virtual soldier subject-position, and experiential realism, which refers to the overall ability for players to experience the feeling of virtually fighting a war.

Apart from these typologies of realism, Pötzsch (2015) stresses that representations of conflict and violence in military-themed and other FPS/TPS games are also very selective in nature. They mostly exclude burdensome aspects of warfare and thus avoid moral ambiguity, in order to let players have a pleasurable gameplay experience. As such, he describes several 
filters that can be found in these games, and which do not allow for, among other aspects, the portrayal of undesired forms of violence such as friendly fire or the targeting of civilians, or the depiction of negative consequences of combat such as physical trauma or PTSD. A group of researchers affiliated to the International Red Cross furthermore stated that military games convey fundamentally undermining messages in relation to the perception of, and respect for, the rules of international humanitarian law (IHL) (Clarke et al. 2013). This was substantiated by a study by Pro Juventute Switzerland and Trial International, which found that games portraying conflict and war included several violations of the rules of IHL, often related to the destruction of civilian property, the wounding or killing of civilians, and the inhuman treatment or torture of prisoners (Castillo 2009).

These studies on realism in military-themed digital games (in a post-1989 setting) have been complemented with specific content analysis, particularly concerning aspects of ideology and the representation of "otherness." Several studies have highlighted how the subsequent versions of the game America's Army, which was created by the US army, can be seen as "virtual advertisements" for the military (e.g., Li 2003; Nieborg 2010; Power 2007), while also other games like Medal of Honor and both Call of Duty 4: Modern Warfare and Call of duty: Modern Warfare 2, created by entertainment companies, convey clear pro-militarist opinions (Gagnon 2010; Van Zwieten 2011). In relation to depiction of "the other," several studies have focused on representations of the Middle East in particular, as the region is shown frequently in such games (Höglund 2008). They highlighted that military-themed shooting games offer stereotyped portrayals of the region, in which no consideration is given to its ethnic and religious diversity (Šisler 2008). Höglund (2008) describes it as a form of "neo-Orientalism," an American set of discursive strategies about the region heir to the British sense of Orientalism, portraying the Middle East as a perpetual war zone, where US interests continuously clash with forms of Islamic radicalism and terrorism.

Combined, the aforementioned studies present an in-depth analysis on how military-themed games offer selective representations of conflict and war. Yet, they only examine the nature of the conflicts represented in the games to a limited extent. This is best shown by the content analysis of narrative elements in military FPS games carried out by Breuer et al. (2012). They found that, among other aspects, some conflicts, such as the Second World War and the war in Vietnam during the 1960s and 1970s, were represented more often than others, while a number of games were also set during the "War on Terror" (abbreviated WoT), based on both real and fictional scenarios. As no clear description of WoT was given, however, it remained unclear what specific conflicts it referred to. Therefore, to offer more clarity, and allow for a more global, less US-centered perspective on contemporary conflicts and the representation thereof in digital games, we chose to study games about conflicts in a post-1989 setting using a more strict definition of "conflict" and "war," as found in the field of peace and conflict studies and the framework provided by the UCDP in particular.

During the 1980s, the Department of Peace and Conflict Research at Uppsala University in Sweden was responsible for the establishment of the UCDP, which tries to provide data about the occurrence of global conflict since 1946 and the end of the Cold War in 1989 in particular. It offers a conceptual framework concerning conflict and war that has become a standard for its systematic study, by identifying both the conditions that are required to speak of conflict or war and the types of conflict that can occur based on the nature of the actors involved. It defines an "armed conflict" as "a contested incompatibility which concerns government and/or territory where the use of armed force between two parties, of which at least one is the government of a state, results in at least 25 battle-related deaths [in one calendar year]"; it defines a "war" as an "armed conflict that results in at least 1000 battle-related deaths." Furthermore, it makes a 
distinction between three types of "armed conflicts": one in which two or more governments are the primary parties in the incompatibility (interstate armed conflict); one in which the incompatibility exists between a government and a non-government party (intrastate armed conflict), and one in which other governments actively provide troop support to a side (internationalized armed conflict). Finally, also "non-state conflicts" and "acts of one-sided violence" are identified, which are, respectively, a conflict in which no government actors are involved, and the use of armed force by a formally organized (state- or non-state-based) group against civilians, both leading to 25 battle-related deaths in 1 year. Concerning the numerical parameters, a conflict or act of one-sided violence is identified as being "inactive" when less than 25 deaths in a year have occurred (for a more comprehensive description, also of additional parameters not taken into account in this study, see UCDP 2016a).

Based on this framework, an overview can be given of how conflicts have evolved since the end of the Second World War and 1989 in particular. First, concerning the types of armed conflict that have occurred since 1946 (see Fig. 1), there has been a near complete disappearance of interstate conflicts in recent years, while the number of intrastate conflicts has increased significantly (its number reached a peak of 47 conflicts in 1991 in the aftermath of the Cold War and the dissolution of the Soviet Union). At the same time, the occurrence of internationalized armed conflict has remained rather stable since the late 1970s, but an upward trend has been observed in recent years. In addition, concerning the regions in which the conflicts have taken place (based on the area classification by UCDP), a majority could be located in Asia and Africa, even though Europe saw an increase during the 1990s and in more recent years. Secondly, in relation to nonstate conflict, an increasing number has been recorded since 1989 (resulting in a higher number of non-state conflicts in comparison to all types of armed conflict combined in recent years), most of which have occurred in Africa and the Middle East (Sundberg et al. 2012). Thirdly, concerning acts of one-sided violence against civilians, a significant number of acts have been recorded, most of which were committed in Africa, Asia, and to a lesser extent the Middle East, while they also have been increasingly committed by non-state actors since 1989 (Eck and Hultman 2007; for the entire paragraph, see Pettersson and Wallensteen 2015).

In comparison to these trends, related to the changing occurrence of conflict/war and organized violence since 1945 and the end of the Cold War, a further analysis can be made of how digital entertainment games depict contemporary, post-1989 "war."

\section{Methods}

In order to study how the notion of contemporary conflict, as defined within the UCDP framework, is conceptualized within popular digital entertainment games, we analyzed the 15 most popular digital "war" game series set in the post-1989 period that were available for the personal computer through the online distribution platform Steam, and were played by the highest number of players as of November 17, 2015. ${ }^{1}$ These choices were made for several reasons. First, we chose the pc as a gaming platform, because it is still considered to be one of the most important platforms available (van Dreunen 2016), and it allows for access to a wide variety of games not found on others, while still including most popular (AAA) titles. Second, we chose for games that

\footnotetext{
${ }^{1}$ The data for this study were gathered as part of a broader research project. As a result, games on Steam that were tagged as “war"-games, but were released after November 17, 2015, such as Homefront: The Revolution by developer Dambuster Studios, were not included in the corpus.
} 


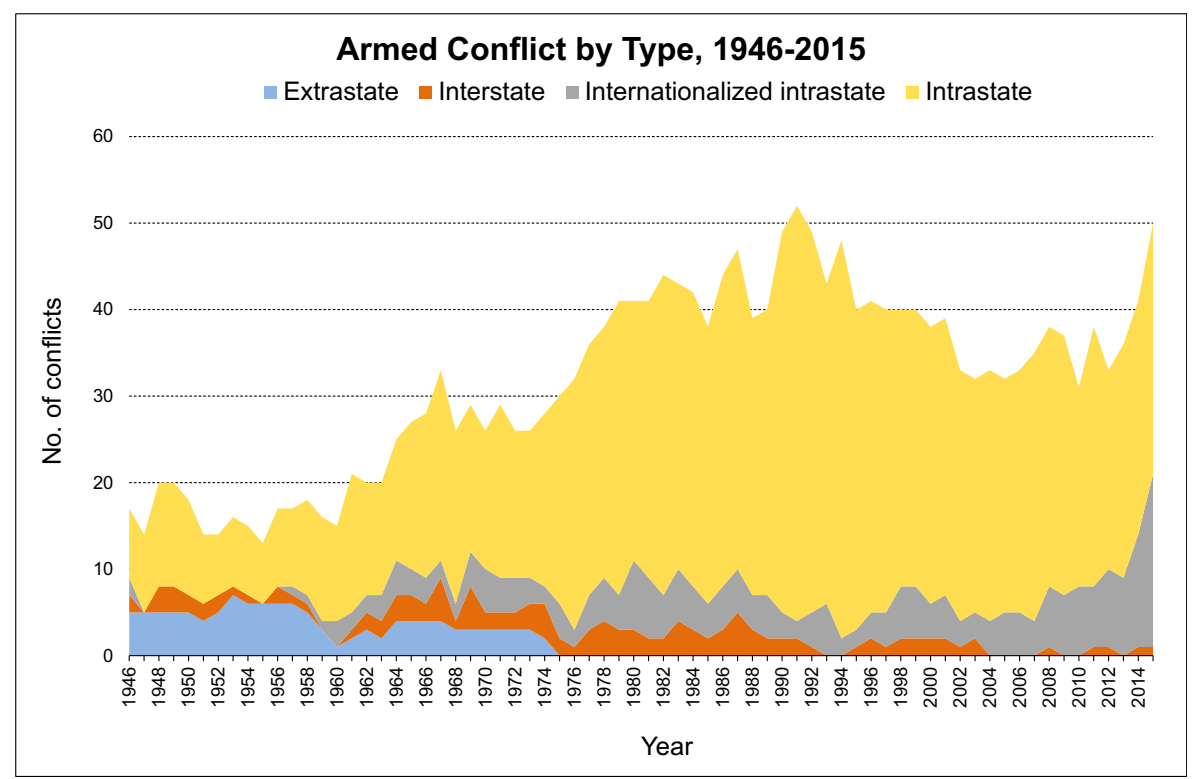

Fig. 1 Armed conflict by type, 1946-2015 (UCDP/PRIO Armed Conflict Dataset). Note. Based on Gleditsch et al. 2002; Melander et al. 2016. Note. UCDP also identifies extra-state armed conflicts, which can be defined as armed conflicts between a state and a non-sovereign entity outside the borders of that state (e.g., a colony). As this type of conflict has not occurred anymore since 1975, it is not discussed in this article

are available on Steam, because digital game downloads have surpassed physical retail sales as the most important form of distribution in recent years (SuperData 2015), and Steam has been the dominant distribution platform since it was launched in 2004 (Edwards 2013). More importantly, using Steam allows us to gain a better insight into the popularity of a broader range of games, as 2015 saw the launch of SteamSpy, a web application that gathers information about games owned and played by Steam users worldwide, based on data of one of Steam's own web API's showing publicly accessible user profile statistics (SteamSpy 2016). A third reason for choosing Steam is its "tagging system": Steam users, and as such both game developers/publishers and gamers, do not only buy or register games through Steam, but can also assign keywords or "tags" to them, in order to help other users search for games in a more targeted way (Valve Corporation 2016). ${ }^{2}$ As such, we looked at the games tagged as "war" games, in order to, in combination with the figures made available through SteamSpy, identify the 15 most popular game series about conflicts in a post-1989 setting. In addition, as these tags are assigned by both game developers/publishers and gamers, they offer a first, albeit limited, indication of how they think about conflict and how it is depicted in games.

In order to study the conceptualization of post-1989 conflict in popular digital games empirically, we first looked at a set of promotional game descriptions made available through Steam (an example can be found in Fig. 2), as these could provide information about the conflicts depicted in the games themselves and the marketing strategies surrounding them. To do so, we selected a "weighted" number of 15 descriptions, by treating the descriptions of the games belonging to the

\footnotetext{
${ }^{2}$ The "tagging" option on Steam allows every Steam user, and therefore also the companies distributing the games on the platform, to assign tags or keywords to specific games, which are subsequently shown when they are applied by a significant number of users (no numerical threshold is mentioned on the Steam support page).
} 
same series (e.g., the Call of Duty games in a contemporary setting) as those of one game, to allow for more diversity within the corpus. As such, we collected a set of 28 game descriptions. To study them, we applied a close reading approach, whereby we paid special attention to "feature"-lists or overviews of remarkable game elements provided by the game developers and/or publishers.

Concerning the study of the games themselves, we made an analysis of a set of narrative elements based on the UCDP framework described above. We identified the armed conflicts, non-state conflicts, and acts of one-sided violence that were represented in the selected games, by looking at the locations in which they took place (i.e., countries, regions), the nature of the actors that were depicted (i.e., armed factions or civilians), and the nature of the confrontations in which they were involved. Based on these results, we also determined whether the actors could be identified as protagonists or antagonists. Concerning the locations, a distinction was made between the five regions recognized by UCDP, i.e., Europe, the Middle East, Africa, Asia, and the Americas, meaning that every country was categorized based on this classification (e.g., Russia as a part of Europe; Afghanistan and Pakistan as a part of Asia rather than the Middle East). Concerning the numerical parameters identified by UCDP-25 battle-related deaths for active conflicts and acts of one-sided violence, 1000 for active wars - it was often difficult to determine whether 1000 virtual deaths had been caused in the game or not, which means that, strictly speaking, we solely identified "conflicts," even when the depiction of a larger conflict (and thus potential "war") was suggested. In cases where the occurrence of conflicts and acts of one-sided violence were mentioned in the game, even though 25 battle-related deaths could not directly be observed, we did code the events as such based on the distinction made between active and inactive conflicts and one-sided violence.

Secondly, we applied this analysis to the games with a single player component, as they offer narrative elements usually not found in multiplayer-based games. In particular, we studied the games within our corpus with a single player "campaign" mode (see also: Breuer et al. 2012), a narrative mode in which players advance through levels in an often linear way and engage with groups of enemies in order to complete a set of predetermined objectives. Especially here, the player is presented with a set of fixed events and actors, and a narrative

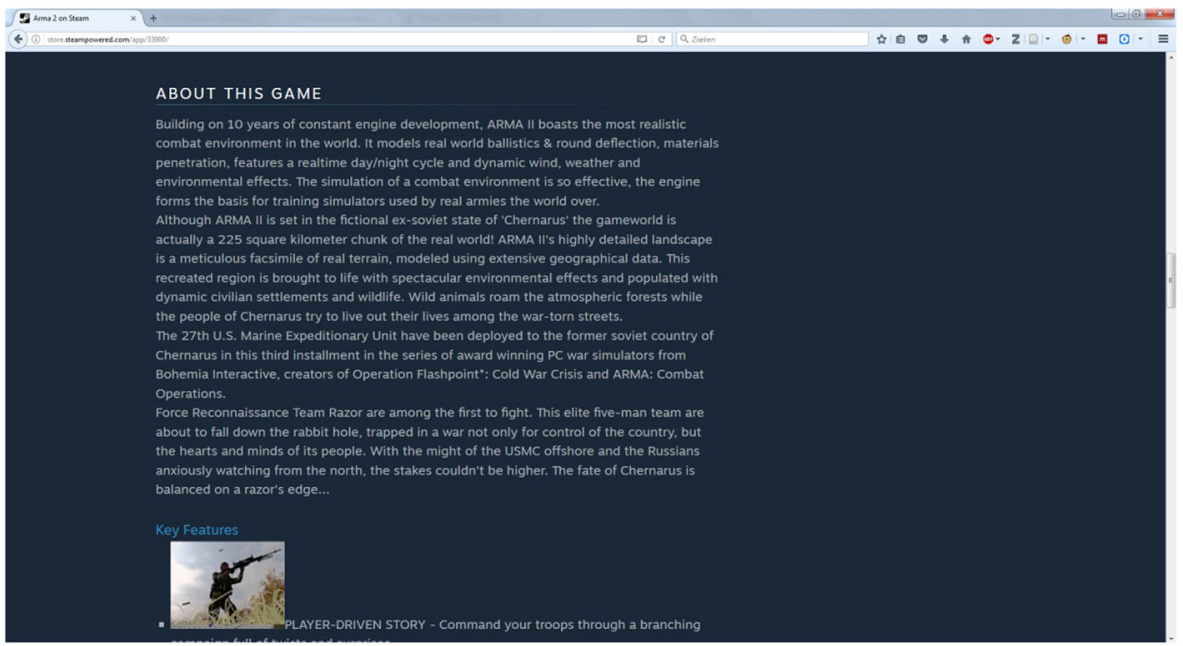

Fig. 2 Screenshot from the promotional game description of the game ArmA II, as found on Steam (Steam 2016b) 
with only one or a few outcomes, meaning that the conflicts they represent can more strictly be identified in comparison to more open-ended games. Following this, we opted for an in-depth analysis of the presented narratives in their entirety (e.g., Van Zwieten 2011), as the nature of the depicted conflicts changes throughout the game and cannot be studied based on timed sequences. In particular, our analysis was carried out using a combined approach, in which we first studied a walkthrough of the selected games published on YouTube, as they provided us with most of the necessary information about the depicted locations, factions, and conflicts, after which we complemented this dataset with information gained through a personal playthrough when further clarification was needed. Based on the presented criteria, a total number of 14 games were studied (that is, the games within the selected corpus of 15 game series/28 games with a single player "campaign" mode), i.e., those belonging to the Call of Duty, ArmA, Battlefield, Spec Ops, and Medal of Honor series (see Appendix 1).

\section{Results}

As part of our analysis, a general characterization of the studied games can be given in terms of origin and release date, based on the overview in Appendix 1. Here, one immediately notices the predominance of the American perspective: seven of the studied series ( 15 of the 28 games in total) were directly created by US-based game developers, while two additional series, i.e., the three games belonging to the Battlefield series and the game Spec Ops: The Line, were released by the American publishers Electronic Arts and 2K Games. Three of the selected series (six games) were developed in Eastern Europe (i.e., the Czech Republic and Poland; the game DCS World was created by Russian developer "Eagle Dynamics" but released by British publisher "The Fighter Collection"), while the remaining games were created by smaller independent studios. Concerning the release date, a majority of the games was published since 2009 (23 of the 28 included games).

\section{Conceptualization of Conflict/War in Promotional Game Descriptions}

Based on the descriptions of the 15 selected game series about war in a post-1989 setting, a majority could be characterized as offering a military perspective, implying a dominance of statebased actors, and thus state-based armed conflict over non-state conflict. This was underscored by the fact that 9 of the weighted game descriptions referred to the ability for players to step into the boots of a member of the armed forces, while 7 of the 15 weighted descriptions explicitly mentioned the armed forces of a specific country, in particular those of the USA. In contrast, we only found references to non-state factions in two of the descriptions, while no further information about these factions was given. In addition, we did not find game descriptions that referred explicitly to the nature of the depicted conflicts, as most of the descriptions were too vague to allow for a more detailed categorization. In terms of game genres, 11 of the included series were based on shooting mechanics ( 9 of which belonged to the FPS genre), while the corpus also included 2 other games centered on combat, i.e., the RTS War, the Game and the military flight simulator DCS World. In all, of the 15 studied game series and the 28 games in total, only 2 of them, i.e., This War of Mine and 60 Seconds, could be characterized as offering a nonmilitary approach to conflict and war.

Secondly, particularly but not solely concerning the military-themed games, a clear emphasis on weaponry and other military equipment was prevalent. Ten of the weighted game descriptions 
included explicit references to the ability for players to use and/or customize a variety of firearms and military vehicles, some of which were very elaborate and specific, as in the case of the promotional description for Call of Duty 4: Modern Warfare:

"Authentic Advanced Weaponry_Featuring an available arsenal of more than 70 new and authentic weapons and gear from assault rifles with laser sites, claymore mines, .50 caliber sniper rifles, and M-249 SAW machine guns. With accessories like night-vision goggles and ghillie suits, for maximum concealment, Call of Duty 4: Modern Warfare has players locked and loaded to accomplish the mission" (Steam 2016c)

Furthermore, a common theme found in the selected game descriptions (especially those of the military-themed games, but also the others) was the intenseness and exciting nature of the gameplay. In 11 of the 15 weighted descriptions, we found statements that, for example, described the games as "action-packed" and "fast-paced," thus characterizing conflict and war as an exciting experience rather than a violent, troublesome confrontation. As such, we also found nuanced differences between these statements, as the makers of games like Call of Duty, ArmA, and Battlefield tend to stress other aspects for promotional reasons. Whereas the descriptions for the Call of Duty games referred to a sense of cinematic intensity and the Battlefield games were presented as offering the "glorious chaos of all-out war," the descriptions of the ArmA games explicitly mentioned the detailed and life-like nature of its environments as "thrilling," and not so much the gameplay itself.

In contrast to this notion of intensity, 11 of the weighted descriptions also contained references to aspects of "realism" and "authenticity." Here, we made a further distinction based on the frameworks presented by Breuer et al. (2012), Payne (2012), and Halter (2006) and Mirrlees (2009). As such, we first of all found that, in relation to the military-themed games in particular, references to subjective realism, or the notion that players can take up the subject position of a soldier, were clearly present, in line with our previous findings on the references to state-based actors and specific national armies. Furthermore, eight of the weighted descriptions referred to the overall sense of experiential realism, often directly linked to descriptions of the exciting nature of the gameplay, as described above.

Second, we found that seven of the weighted descriptions referred to either the realistic nature of the presented gameplay, the functioning of available weaponry, the behavior of nonplayer characters, or the environments players could interact with, all of which can be seen as forms of behavioral realism, or realism related to interactions between players and the game world. At the same time, however, three of these descriptions also contained clear links to forms of representational realism, or realism related to the audiovisual presentation of the game, because the distinction between the two was not clear. A good example thereof is the following quote, from the description of the game America's Army 3 (aspects of behavioral realism are underlined once, aspects of representational realism twice; keywords that are connected to both are italicized):

"Built on the Unreal Engine 3, AA3 delivers stunningly realistic characters, environments, lightning effects, animations, and team-based experiences. In the game where Every $\overline{\overline{\text { Detail Counts }}}{ }^{\mathrm{TM}}$, players are bound by Rules of Engagement (ROE) and gain experience as you navigate challenges in team-based, multiplayer, force-on-force operations." (Steam 2016a) 
In addition, four of the weighted game descriptions stated that the game in question was inspired by real-life events or was set in a "realistic present-day setting." This refers to aspects of narrative realism, or the realistic nature of the settings, locations, and actors involved. Here too, we only identified brief and vague connections to identifiable conflicts, in line with the previous findings. Furthermore, we found a specific reference to narrative realism, which can be seen as an example of behavioral realism as well, in the description of the game Spec Ops: The Line, as it stated that the game "explores the dark side of war in a realistic way, [as] there are no good outcomes, only hard choices" (Steam 2016d). It is an instance of a more reflective approach to conflict, as the player is forced to make difficult choices throughout the game (see also Payne 2014; Pötzsch 2015). However, this approach was only found in one other game within the selected corpus, i.e., This War of Mine, and is thus very rare. Therefore, one can say that most of the descriptions, while referring to an exciting gameplay experience and, in case of the military games, the ability to play as a soldier, they also try to include (other) references to "realism," but mainly by referring to very specific elements such as the way in which a firearm works.

Concluding, most of the studied descriptions provided little to no information about the nature of the conflicts represented in the games, even though they did lay bare the predominantly military, and thus state-based perspective found in them. At the same time, they primarily described "war" as a spectacle rather than a cause of violence and destruction, highlighting the use of weaponry, the ability for players to step into the boots of a soldier, and other, very specific, aspects of "realism." As such, elements of representational realism were not stressed more prominently than others, meaning that elements of subjective, experiential, behavioral, and narrative realism were deemed equally relevant in marketing strategies, which corroborates Payne's (2012), and Halter's (2006) and Mirrlees' (2009) analysis. Aspects of representational realism on the other hand were perhaps taken for granted, as most gamers have already come to expect a high-quality audiovisual representation. Taken together, the results also lay bare a more fundamental aspect of these games, in particular in relation to how developers and publishers respond to the interests of the players; that is, that most of these developers and publishers, as they operate within a competitive global market, still seem to consider a more reflective exploration of the nature of contemporary conflict, e.g., from a nonmilitary perspective, to be commercially unviable and/or irrelevant. This can be attributed to what we would call a "presumed burden of interactivity" of games in comparison to other media like film, when depicting conflict; that is, that whereas creators of "war" movies frequently prioritize character development and emotional involvement over action in their portrayal of conflict, designers of "war" games still tend to stress the latter and include, for example, shooting mechanics, because games need engaging systems to be profitable, and shooting mechanics are perceived to be very successful and "safe," in that respect. In contrast, other, more innovative approaches not centered on armed combat are only explored to a limited extent.

\section{Conceptualization of Conflict/War in Narrative Content in Single Player Games}

Locations In order to study in what locations (i.e., countries, regions) the 14 digital "war" games with a single player campaign mode were set, we identified in what country each level of the games took place, in order to give a comprehensive overview. To do so, we made a distinction between real and fictional country-locations, and determined in what region (identified by UCDP) the fictional countries could be located, based on the information found 
in the game or in some of its paratexts, such as the promotional game descriptions studied above.

The 14 games in our corpus contained 237 levels in total. Of these, 17 levels $(0.7 \%)$ could not be identified. This was the case in the games Call of Duty 4: Modern Warfare, which is partly set in an unidentified Middle Eastern country, and Battlefield: Bad Company 2, which predominantly takes place in Latin America, but in many levels without offering clear indications about the country being portrayed. The small percentage of non-identifiable country-locations does not mean that clear information was always provided however, as we identified many of the depicted countries indirectly, e.g., through information about specific cities or regions briefly shown on a map in intermediary cutscenes or in introductory mission briefings. An overview of both the real and fictional locations (countries and regions) that were identifiable can be found in Fig. 3.

Of the 14 games that were studied, 4 games (those belonging to the ArmA series) took place in an identifiable fictional setting; and as such, all of the ArmA games were set in either one country or two adjacent ones (number of levels: 93). Based on the information provided in the game or in their paratexts, we were able to further identify three of the five country-locations as being set in Europe and the Middle East or Asia (for example, the game ArmA II is set in the country Chernarus, which is described as a "fictional [European] ex-soviet state" (Steam 2016b)), while two others were described vaguely and could not be located in a specific region.

When looking at the overview of the real, identifiable country-locations (number of levels: 116; see Fig. 3), one immediately notices the high number of levels set in the United Arab Emirates (UAE), the USA, Afghanistan, and Russia. In the case of the UAE, this is mostly explained by the fact that the game Spec Ops: The Line, which consists of 15 levels, is set exclusively in the UAE; in the case of Afghanistan, this is to a lesser extent explained because it is the setting of the 10 levels included in the game Medal of Honor. Levels in the USA and Russia were identifiable in multiple games (four and four, respectively). Other countries were featured six times or less in the levels included in the corpus.

In relation to the regions portrayed in the studied levels as identified by UCDP, a relatively equal number of levels set in existing countries took place in Europe (32 or 27.6\%), Asia (28 or $24.1 \%$ ), the Americas ( 27 or $23.3 \%$ ), and the Middle East (26 or 22.4\%), while especially Europe gained more prominence when we also included the regions in which the fictional countrylocations were set ( 89 of 209 levels or 42.6\%). In contrast, we only found that 3 of the 116 levels set in existing countries, and of the 209 levels in identifiable country-locations in general, took place in Africa (2.6 and 1.4\%, respectively). This means that especially the Americas and Europe are over-represented as areas of conflict, while locations in Africa are almost entirely absent, even though some of the most deadly and destructive conflicts and acts of one-sided violence since 1989 have taken place in Rwanda, Ethiopia, the Democratic Republic of Congo DRC, and Sudan, to name but a few countries (UCDP 2016b).

Furthermore, we observed some significant additional trends when not taking into account the regional categories offered by UCDP. First, a predominance of Middle Eastern countries among existing locations (45 of 116 levels, or 38.8\%) becomes visible when Afghanistan and Pakistan are considered to be a part of the Middle East as well, as is often done. As a consequence, only nine levels could be located in Asian countries like China, India, the Philippines, Kazakhstan, and Singapore, meaning that conflict-ridden countries like Sri Lanka, Myanmar, and Nepal were not depicted, while India and the Philippines, which have seen very destructive episodes of (armed) conflict and one-sided violence since 1989 as well, were hardly represented (each in only 2 of the 116 levels, or $1.7 \%$ ). Second, a significant number of existing country-locations are set in former member states of the 


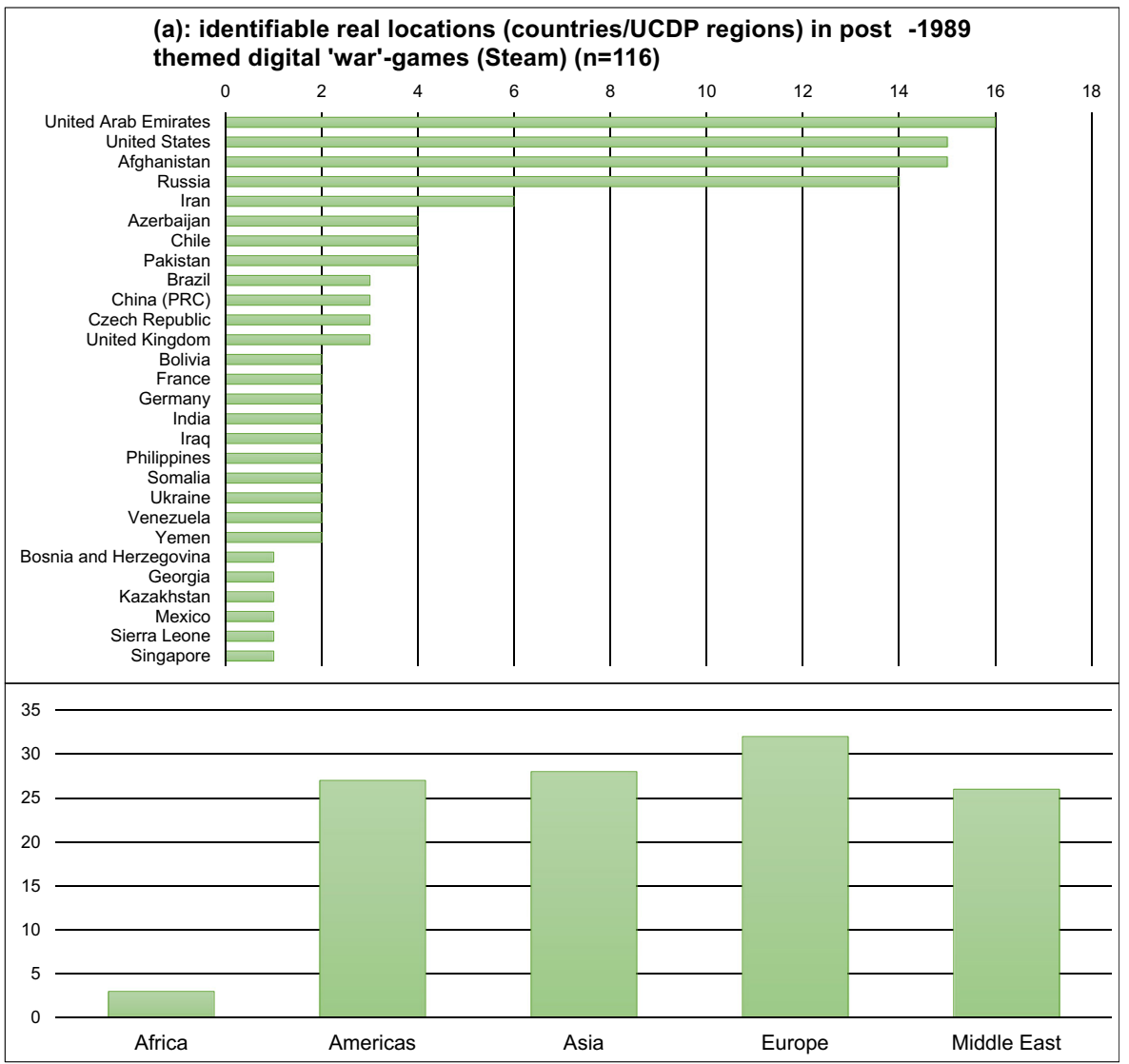

Fig. 3 Identifiable locations (countries/UCDP regions) in post-1989-themed digital "war" games (Steam) $(n=209)$

Soviet Union (22 of the 116 levels, or 18.9\%) and the Eastern Bloc (25 levels or 21.6\%), an observation which holds true for fictional country-locations as well (18 of the 93 levels, or $19.4 \%$, were set in the fictional former Soviet republic of Chernarus). Concerning Europe, one notices the prominent place taken up by France, Germany, and the UK, while only one level portraying real-world locations was set in the Balkan area (i.e., in Bosnia and Herzegovina), even though the region has seen very violent episodes of conflict during the early 1990s.

We can thus conclude that some countries and regions, like the USA and Russia, the Middle East and the former Eastern Bloc, are prominently represented in the studied games, while other, often more conflict-dense areas like Africa, are essentially ignored in comparison to the real-world developments since 1989 as recorded by UCDP. This can primarily be explained by the dominance of the US perspective, as a majority of the studied games were developed and/ or published by companies active in the USA, or at least partly so, as shown above. As a consequence, especially regions that are recognizable for American, and to a lesser extent European, gamers - the audiences these games usually target (Kohler 2010) — or regions that are of a geopolitical interest to the USA, are depicted. This is especially true for the Middle 


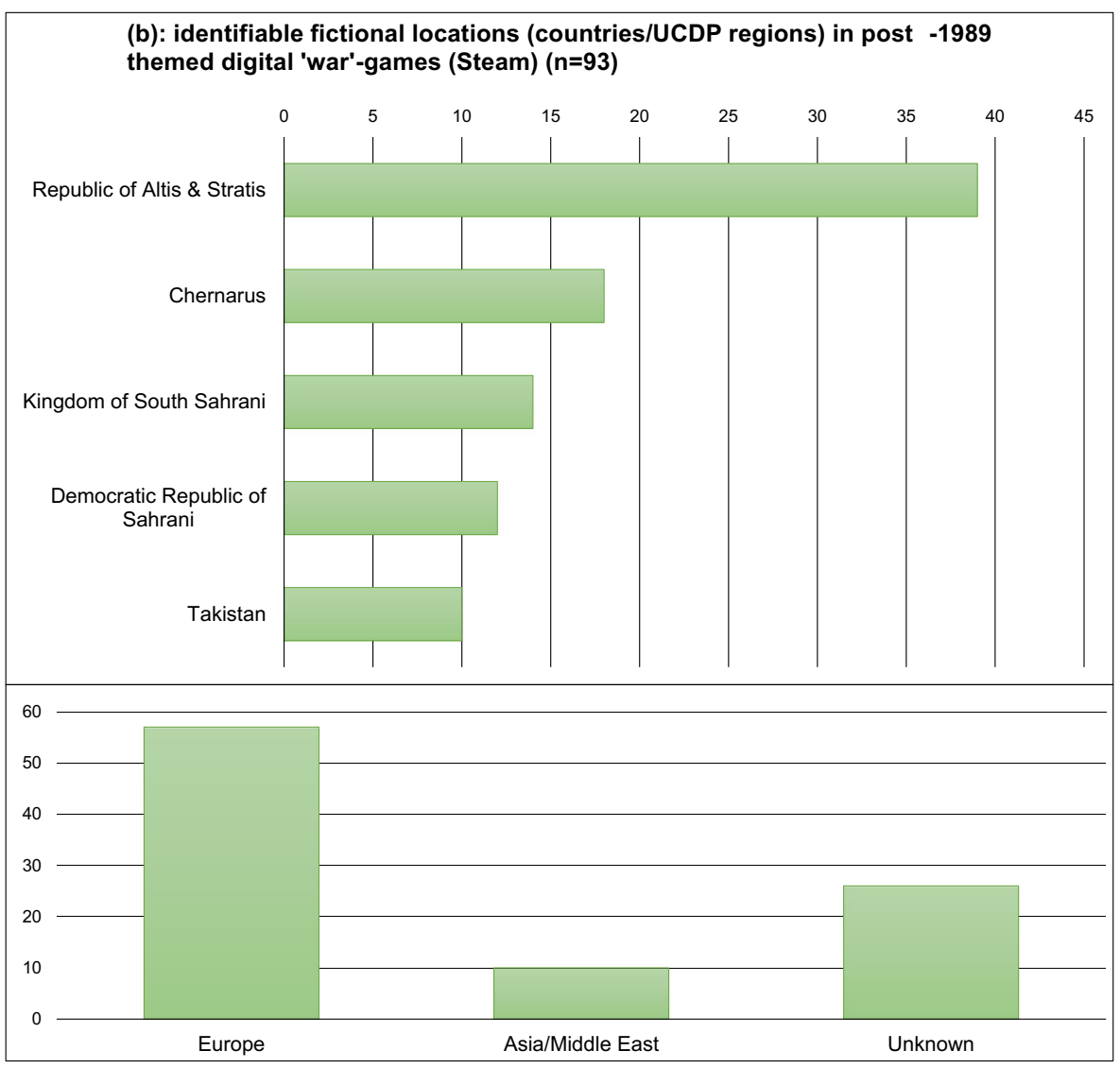

Fig. 3 (continued)

East, which features prominently in these games, meaning that the sense of neo-Orientalism as described by Höglund (2008) is still very present in the popular "war" games published since 2009 (see Appendix 1). The same holds true for the depiction of the USA itself and Latin American countries, which corresponds to a fear of potential future conflicts that was already identified by Breuer et al. (2012). Also the absence of games set in African locations can be explained as such. Here, the only African country that appeared in two of the studied levels was Somalia, which saw a brief US-led intervention sanctioned by the United Nations in 1992-1993 that was also depicted in the very successful movie Black Hawk Down (IMDb 2016). This specific geographical representation implies that the narrative content of popular digital games about "war" shines a very selective light on the conflict areas around the world, and creates a narrow image of where "wars" have occurred since 1989.

Factions and Conflicts/Acts of One-Sided Violence Based on our previous analysis of the 15 weighted game descriptions, a majority of the selected games could already be characterized as offering a military, and therefore state-based perspective on "war." This was especially the case for the Call of Duty, ArmA, Battlefield, Spec Ops, and Medal of Honor games, which means that these games are likely to portray aspects of state-based, and thus 


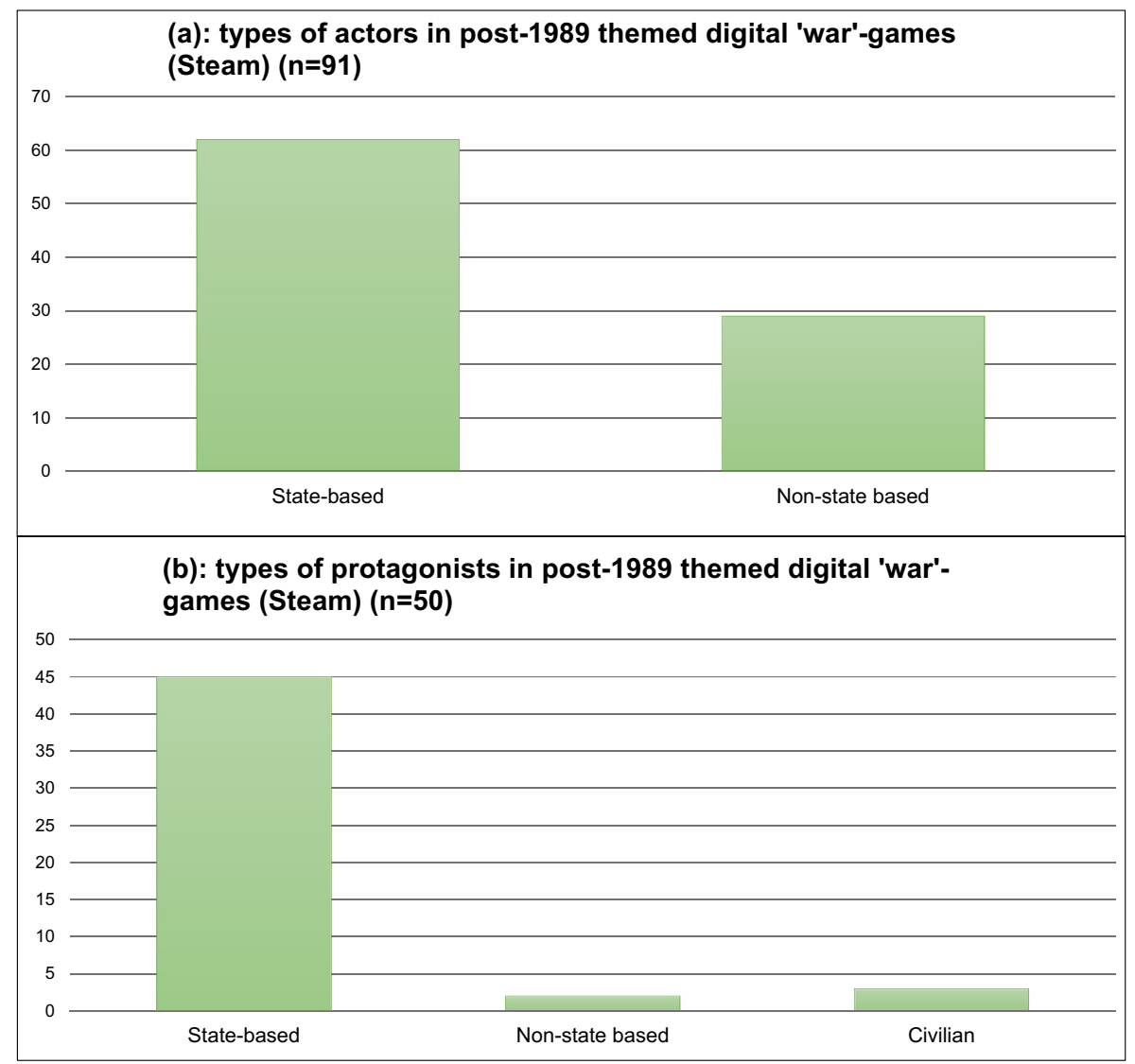

Fig. 4 Actors/protagonists in post-1989 themed digital "war” games (Steam)

armed conflict over episodes of non-state conflict. Nevertheless, further analysis of the game content was required to find out which specific factions and conflict types were represented. Therefore, an in-depth study of the selected game narratives was carried out using the framework described above.

Based on the overview found in Fig. 4, we identified a set of 91 factions, of which 62 could be characterized as state-based $(68.1 \%)$ and 29 as non-state-based factions $(31.9 \%) .{ }^{3}$ Furthermore, when looking at whether the protagonists belonged to state- or non-state factions, we found that almost all of them were state-based, i.e., belonging to the armed forces of the USA, the UK, or Russia. This confirms our previous findings on the military perspective found in the promotional descriptions. Only twice, players could play as a member of a non-state actor, but in both cases the protagonists were identified as undercover-agents working for a state-based actor (the US government). Furthermore, "Task Force 141 (Disavowed)," another (fictional) non-state actor, was found in the game Call of Duty: Modern Warfare 3, but this armed faction was rather closely connected to several state-based actors, as it actively fought for the interests

\footnotetext{
${ }^{3}$ A number of 103 actors could be identified when taking into account all the vaguely referenced governmental actors in the game Call of Duty: Ghosts who united to form "The Federation." As such, 74 actors could be characterized as state-based (71.8\%), while 29 could be characterized as non-state-based (28.2\%).
} 
of the US and UK government. In three additional levels, the player could step into the shoes of a civilian or a political prisoner, but one of them eventually also joined the US armed forces. The two others were either executed or killed by an act of one-sided violence. The antagonists (and their allies) could be identified as both state-based and non-state factions, which means that no significant distinction was made in that respect.

Secondly, when looking at the types of conflict represented in the games (see Fig. 5), we identified a total number of 45 conflicts, of which a majority were interstate in nature (28 or $62.2 \%)$. In contrast, we only found five non-state conflicts $(11.1 \%$ ) - three of which involved "Task Force 141 (Disavowed)," the same fictional non-state actor closely affiliated to the US and UK government mentioned above - eight internationalized (17.8\%), and four intrastate conflicts (8.9\%). Especially concerning the intrastate conflicts, we can even state that they were hardly depicted at all, as they were usually shown as the incidents leading up to a broader (US/ UK-led) international intervention (two of the four intrastate conflicts were only mentioned, and not explicitly depicted in the game). It means that in popular "war"-themed games, which are also identified as such, contemporary, post-1989 conflict is still largely seen as a (direct)

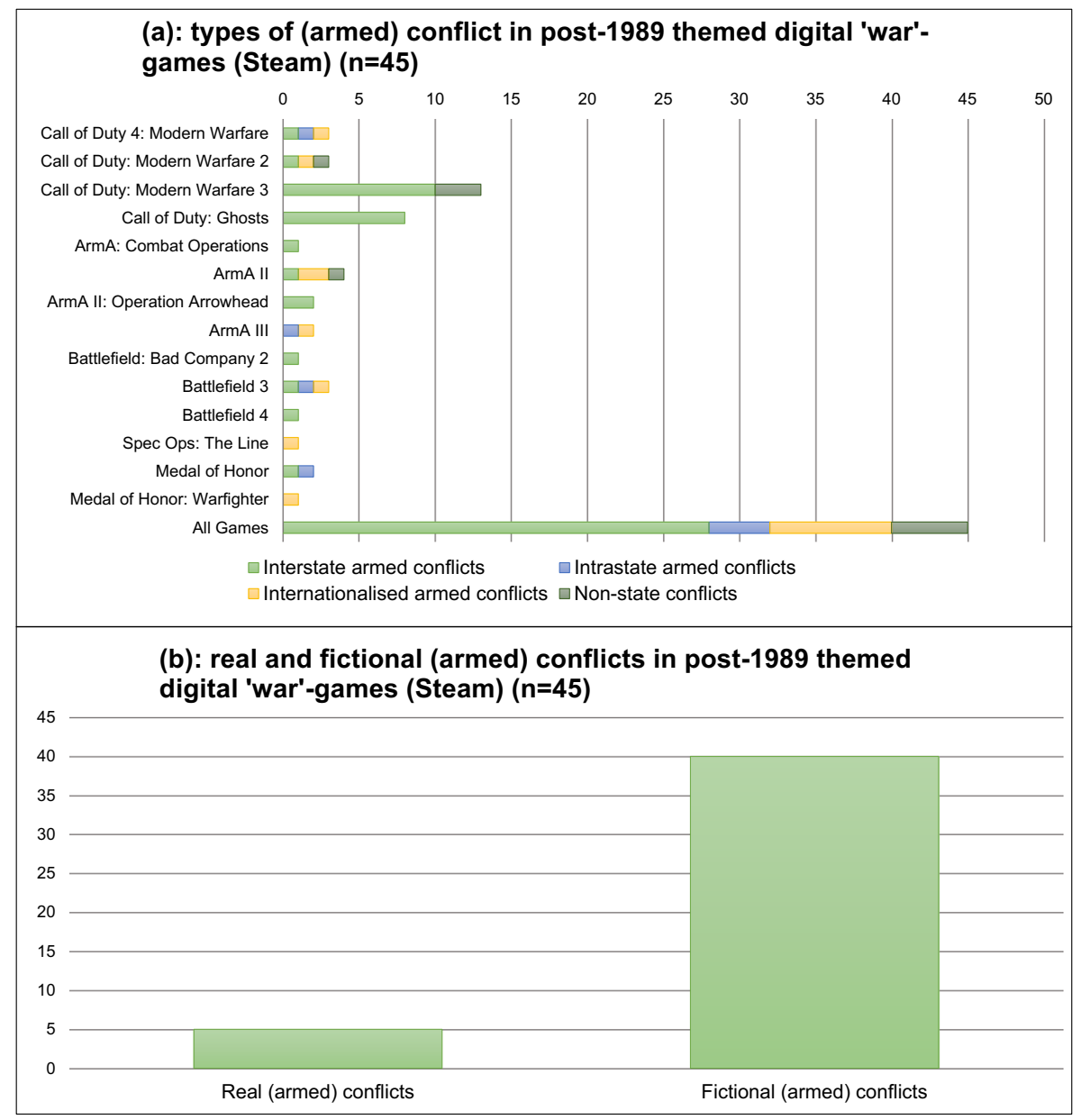

Fig. 5 Armed/non-state conflicts in post-1989 themed digital "war" games (Steam) 
confrontation between major military powers such as the USA and Russia, while intrastate and non-state conflicts, which make up the majority of today's conflicts around the world, are almost entirely ignored. It can to a significant extent be explained by the importance of weaponry already identified above: especially the major powers like the US and Russia have extensive standing armies and can dispose of a wide variety of weapons, which makes it interesting for developers and publishers to create scenarios in which these state-based actors are involved. In the case of the games from, for example, the Battlefield series, it can also be attributed to aspects of gameplay: here, the developers attempt to create large-scale battle scenarios involving vehicular warfare while also trying to provide for a balanced multiplayer gaming experience, which leads them to choose a set of factions of which can be assumed that they are more or less equal in terms of armed capacity.

Furthermore, in relation to the real or fictional nature of the represented conflicts, only two of them $(4.4 \%)$ could directly be identified as real ones (i.e., the conflicts related to the US intervention in Afghanistan depicted in the game Medal of Honor), while three conflicts (6.7\%) either indirectly or vaguely referred to confrontations that have occurred in the real world as well (i.e., in Afghanistan, Iraq, and the Philippines). In all, most of the represented conflicts were fictional in nature. This can be explained by the often very controversial nature of recent conflicts, and of contemporary history in general: it is often interpreted and remembered very

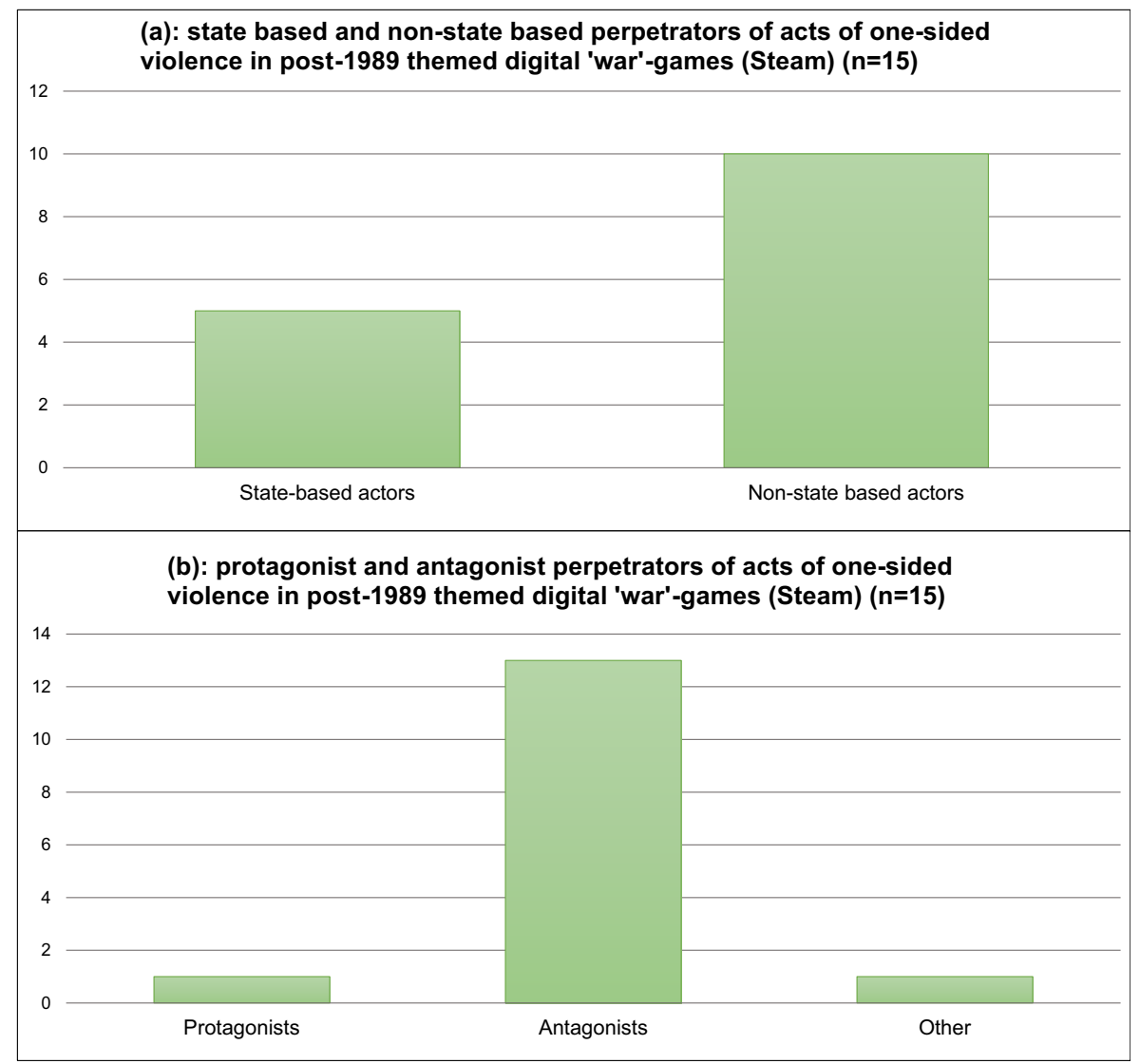

Fig. 6 Acts of one-sided violence in post-1989 themed digital "war" games (Steam) 
differently by different groups, and thus easily subjected to political struggle (see for example the editorial note for the first issue of the Journal of Contemporary History: Laqueur and Mosse 1966). As a result, most developers and publishers tend to avoid this controversy, as it can negatively influence reputation and sales. A famous example in that respect, which was not included in the corpus, is the game Six Days in Fallujah, made by developer Atomic Games in 2009, which was meant to recreate the "Battle of Fallujah" during the US-led invasion of Iraq in 2004, but was ultimately canceled due to criticisms referring to the thousands of civilians that were killed during the assault, and statements claiming that it was inappropriate to recreate these atrocities in a game (Parker 2012). It also holds true for the game Medal of Honor, which was partly adapted by the developers after controversy arose about the fact that players would be able to play as a member of the Taliban (Van Zwieten 2011).

Finally, concerning acts of one-sided violence (see Fig. 6), 15 of them could be identified based on actual scenes in the game or other information provided through briefings or game dialogue. Of these acts, a majority (10 or $66.7 \%$ ) were committed by non-state factions, while four $(33.3 \%)$ were carried out by governments, which corresponds to the trends observed by UCDP. Concerning the involvement of protagonists and antagonists, only one act was committed by a protagonist (i.e., in the game Call of Duty: Modern Warfare 2, in which an American undercover agent participates in a terrorist attack on a civilian airport; in the game Spec Ops: The Line, where the player, as a member of a group of American soldiers, carries out a phosphorus attack on a group of civilians, he or she is first under the impression that he/she is targeting a group of opposing soldiers, making it an example of collateral damage rather than an act of one-sided violence, as defined by UCDP). All the other acts of one-sided violence were committed by the antagonists in the game. This confirms the statements by Pötzsch (2015) about the selective nature of the representation of conflict and violence in many FPS/TPS games as cited above, i.e., that these games include specific filters that do not allow players to carry out undesired forms of violence to precipitate a pleasurable gameplay experience.

\section{Discussion}

This paper reports an analysis of 15 popular "war"-themed game series in a post-1989 setting, in order to find out how the notion of contemporary "war" was conceptualized therein. As such, we carried out a close reading of the promotional descriptions for these games as found on the pcplatform Steam, and an analysis of the narrative of 14 of these games, based on the conceptual framework of "conflict" developed by the UCDP. We conclude that in the studied popular digital games about war, the notion of "war" is conceptualized in a specific and limited way. More specifically, popular "war"-themed games tend to offer a conceptualization of conflict and war that focuses on (1) (direct) confrontations between the major military powers, i.e., the types of conflict that were more common during the nineteenth and first half of the twentieth century, and have become less frequent since 1945 and by the end of the Cold War in particular; (2) military technology and exciting, morally unambiguous combat that is promoted as "realistic" in very specific ways; (3) conflict areas that partly, but only vaguely correspond to contemporary geopolitics, primarily in order to play into a sense of recognition among American/European gamers; and (4) fictional scenarios rather than real ones, as real post-1989 conflicts are mostly considered to be too controversial and as such hazardous from a commercial point of view. In relation to the predominance of large-scale confrontations between the great military powers, this 
has important ideological implications, as it potentially reinforces a misconception of the nature of contemporary warfare, and perceptions of a continued relevance of large standing armies and extended military expenditures, at a time when this is not necessarily the case. Following Stahl's discussion on the militarization of cultural space through interactive "militainment" (Mirrlees 2009; Stahl 2006; see above), it could even normalize the inevitability of future mobilizations for war, even though here, Festl et al. (2013) have shown that it is too straightforward to assume that players would directly adopt such a position. Further research into how players think about the nature of "war" itself, however, is certainly required. Furthermore, concerning the predominantly fictional nature of the depicted conflicts, future research needs to address the reasons why games about contemporary conflicts are considered to be controversial, and by whom. In that respect, the idea of the inherently trivializing nature of the ludic frame connected to digital games, as described by Chapman and Linderoth (2015), could provide a starting point for further research.

The current article aims to contribute to the study of popular digital games and how they represent (armed) conflict. The usage of the conceptual framework on conflict developed by UCDP allowed us to gain a more structural and comprehensive perspective on the changing nature of contemporary conflict, and how this is reflected in popular "war" games. The use of data provided by Steam and SteamSpy allowed us to assess the popularity of a broad range of games, and at the same time identify which ones were considered to be "war" games. However, the results gathered must be approached with some caution, as additional questions can be asked. This for example applies to our decision to study games for the pc available through Steam. Consequently, we did not include games that were either made exclusively for other platforms, were not accessible through Steam, or were mostly downloaded illegally. This is particularly the case for games that are made in Asian countries like China or Japan, as they are usually accessible through separate game clients, or primarily made for consoles, as is the case for many Japanese games (deWinter 2015). Future research should therefore explore how war is depicted in these, for American and European audiences rather unfamiliar, games, e.g., through a comparative analysis.

Furthermore, the choice to study games that are tagged as "war" games implies that games that also revolve around (armed) conflict, but were not tagged as such, were not included in the corpus. This for example applies to the games from the Far Cry series, which are often centered around instances of non-state conflict - the game Far Cry 2 for example takes place in an unidentified African country in which several non-state factions are engaged in conflict — but are tagged as "open world" "adventure" games set in exotic locations, and not as "war" games. This implies that these games are perceived rather differently, meaning that also here, subsequent research should focus more directly on the players, as they experience and appropriate the games in diverse ways. This particularly applies to pcgames that include mission editing and modding tools, such as those from the ArmA series, as it allows players to create personal scenarios centered on conflicts that are usually ignored by commercial developers and publishers.

\section{Compliance with Ethical Standards}

Conflicts of Interest The authors declare to have no potential conflicts of interests with respect to the research, authorship and/or publication of this article.

Ethical Approval This article does not contain any studies with human participants performed by any of the authors. 


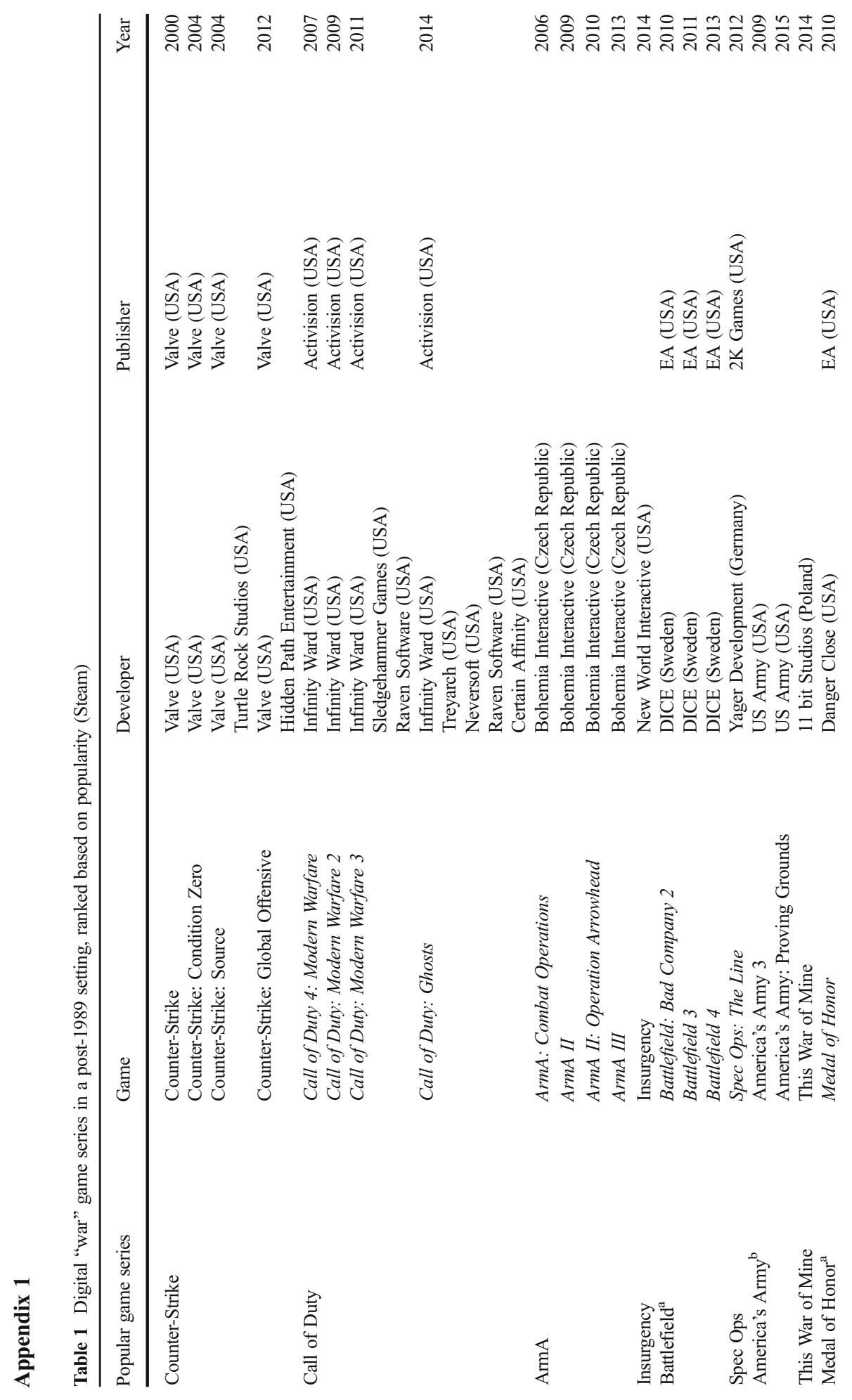




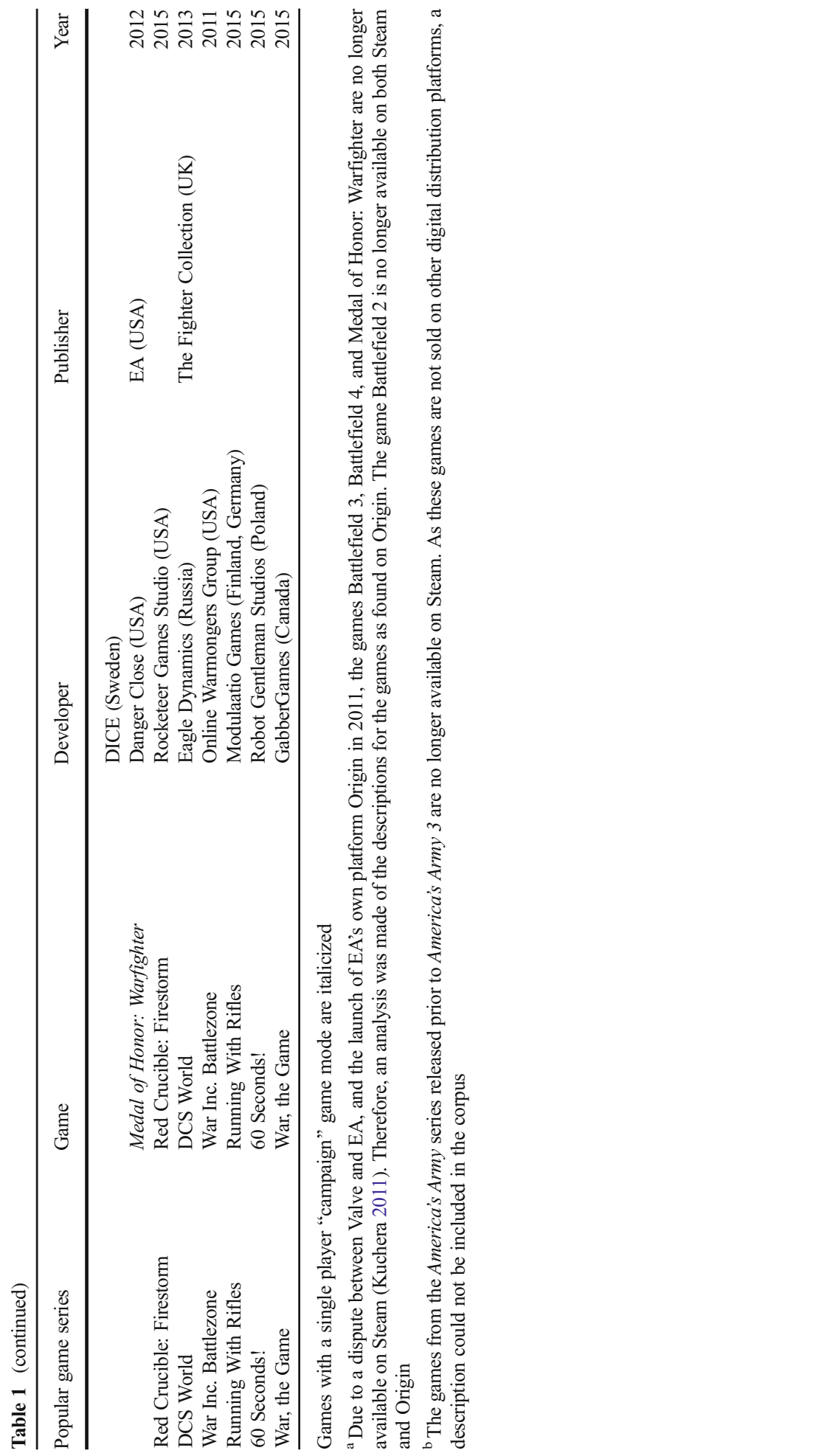


Funding The research reported here has received funding from the Erasmus University Rotterdam under the Research Excellence Initiative programme, "War! Popular Culture and European Heritage of Major Armed Conflicts". The authors would like to thank prof. Maria Grever, prof. Stijn Reijnders, prof. Francisca de Jong, dr. Susan Hogervorst, Siri Driessen and Laurie Slegtenhorst for their valuable feedback.

Open Access This article is distributed under the terms of the Creative Commons Attribution 4.0 International License (http://creativecommons.org/licenses/by/4.0/), which permits unrestricted use, distribution, and reproduction in any medium, provided you give appropriate credit to the original author(s) and the source, provide a link to the Creative Commons license, and indicate if changes were made.

\section{References}

Black, J. (2010). The age of total war, 1860-1945. Plymouth: Rowman \& Littlefield Publishers.

Breuer, J., Festl, R., \& Quandt, T. (2012). Digital war: an empirical analysis of narrative elements in military firstperson shooters. Journal of Gaming \& Virtual Worlds, 4(3), 215-237. doi:10.1386/jgvw.4.3.215_1.

Busselle, R., \& Bilandzic, H. (2008). Fictionality and perceived realism in experiencing stories: a model of narrative comprehension and engagement. Communication Theory, 18(2), 255-280. doi:10.1111/j.14682885.2008.00322.x.

Castillo, F. (2009). Playing by the rules: applying International Humanitarian Law to video and computer games. Geneva/Zürich. Retrieved from https://trialinternational.org/wp-content/uploads/2016/05/Playing_by_the_ Rule.pdf.

Chapman, A., \& Linderoth, J. (2015). Exploring the limits of play. A case study of representations of Nazism in games. In T. E. Mortensen, J. Linderoth, \& A. M. Brown (Eds.), The dark side of game play. Controversial issues in playful environments (pp. 137-153). New York: Routledge.

Clarke, B., Rouffaer, C., \& Sénéchaud, F. (2013). Beyond the call of duty: why shouldn't video game players face the same dilemmas as real soldiers? International Review of the Red Cross, 94(886), 711-737. doi:10.1017/S1816383113000167.

deWinter, J. (2015). Japan. In M. J. P. Wolf (Ed.), Video games around the world (pp. 319-344). Cambridge: MIT Press.

Dyer-Witheford, N., \& De Peuter, G. (2009). Games of empire: global capitalism and video games. Minneapolis: University of Minnesota Press.

Eck, K., \& Hultman, L. (2007). One-sided violence against civilians in war: insights from new fatality data. $J$ Peace Res, 44(2), 233-246. doi:10.1177/0022343307075124.

Edwards, C. (2013). PC Games King seeks to dethrone Sony, Microsoft Consoles. Retrieved from https:/www. bloomberg.com/news/articles/2013-09-26/pc-games-king-seeks-to-dethrone-sony-microsoft-consoles.

Festl, R., Scharkow, M., \& Quandt, T. (2013). Militaristic attitudes and the use of digital games. Games and Culture, 8(6), 392-407. doi:10.1177/1555412013493498.

Gagnon, F. (2010). "Invading your hearts and minds": Call of Duty®and the (re)writing of militarism in U.S. digital games and popular culture. European Journal of American Studies, 5(3), 20. doi:10.4000/ejas.8831.

Galloway, A. R. (2004). Social realism in gaming. Game Studies: The International Journal of Computer Game Research, 4(1). Retrieved August 17, 2017 from http:/www.gamestudies.org/0401/galloway/.

Gleditsch, N. P., Wallensteen, P., Eriksson, M., Sollenberg, M., \& Strand, H. (2002). Armed conflict 1946-2001: a new dataset. Journal of Peace Research, 39(5), 615-637. doi:10.1177/0022343302039005007.

Halter, E. (2006). From Sun Tzu to Xbox: war and video games. New York: Thunder's Mouth Press.

Herz, J. C. (1997). Joystick nation: how videogames gobbled our money, won our hearts and rewired our minds. London: Abacus.

Höglund, J. (2008). Electronic empire: Orientalism revisited in the military shooter. Game Studies: The International Journal of Computer Game Research, 8(1). Retrieved August 17, 2017 from http:/gamestudies.org/0801/articles/hoeglund.

Huntemann, N., \& Payne, M. T. (2010). Joystick soldiers: the politics of play in military video games. New York: Routledge.

IMDb (2016). Top-US-grossing war feature films. Retrieved November 30, 2016, from http://www.imdb. $\mathrm{com} / \mathrm{search} /$ title?genres=war\&sort=boxoffice gross us\&title type=feature.

Infinity Ward (2016). Infinity ward behind the scenes 2016 - Call of Duty® Heritage-YouTube. Retrieved November 22, 2016, from https://www.youtube.com/watch?v=VJcm1sgyZCU. 
Kline, S., Dyer-Witheford, N., \& De Peuter, G. (2005). Digital play: the interaction of technology, culture, and marketing. Montreal: McGill-Queen's University Press.

Kohler, C. (2010). In Japan, gamemakers struggle to instill taste for western shooters | WIRED. Retrieved November 30, 2016, from https:/www.wired.com/2010/09/western-games-japan/.

Kuchera, B. (2011). Battlefield 3 is not coming to Steam, but EA has a real reason. Retrieved December 8, 2016, from http://arstechnica.com/gaming/2011/08/battlefield-3-not-coming-to-steam-ea-provides-good-reason/.

Laqueur, W., \& Mosse, G. L. (1966). Editorial Note. Journal of Contemporary History, 1(1), iii-ivi.

Lenoir, T. (2002). Fashioning the military-entertainment complex. Correspondence: An International Review of Culture and Society, 10, 14-16.

Li, Z. (2003). The potential of America's Army, the video game as civilian-military public sphere. Massachusetts Institute of Technology. Retrieved from https://dspace.mit.edu/handle/1721.1/39162.

Malliet, S., \& de Meyer, G. (2005). The history of the video game. In J. Raessens \& J. Goldstein (Eds.), Handbook of computer game studies (pp. 23-45). Cambridge: MIT Press.

Melander, E., Pettersson, T., \& Themnér, L. (2016). Organized violence, 1989-2015. Journal of Peace Research, 53(5), 727-742. doi:10.1177/0022343316663032.

Mirrlees, T. (2009). Digital militainment by design: producing and playing SOCOM: U.S. Navy SEALs. International Journal of Media and Cultural Politics, 5(3), 161-181. doi:10.1386/macp.5.3.161_1.

Nieborg, D. (2010). Training recruits and conditioning youth: the soft power of military games. In N. B. Huntemann \& M. T. Payne (Eds.), Joystick soldiers: the politics of play in military video games (pp. 5366). New York: Routledge.

Parker, L. (2012). Six Days in Fallujah: the untold story. Retrieved December 7, 2016, from http://www. gamespot.com/articles/six-days-in-fallujah-the-untold-story/1100-6396567/.

Payne, M. T. (2012). Marketing military realism in Call of Duty 4: Modern Warfare. Games and Culture, 7(4), 305-327. doi:10.1177/1555412012454220.

Payne, M. T. (2014). War bytes: the critique of militainment in Spec Ops: The Line. Critical Studies in Media Communication, 31(4), 265-282. doi:10.1080/15295036.2014.881518.

Pettersson, T., \& Wallensteen, P. (2015). Armed conflicts, 1946-2014. Journal of Peace Research, 52(4), 536550. doi:10.1177/0022343315595927.

Pötzsch, H. (2015). Selective realism: filtering experiences of war and violence in first- and third-person shooters. Games and Culture, 1-23. doi:10.1177/1555412015587802.

Power, M. (2007). Digitized virtuosity: video war games and post-9/11 cyber-deterrence. Security Dialogue, $38(2), 271-288$.

Šisler, V. (2008). Digital Arabs: representation in video games. European Journal of Cultural Studies, 11(2), 203-219 Retrieved from http://ecs.sagepub.com/content/11/2/203.short.

Stahl, R. (2006). Have you played the war on terror? Critical Studies in Media Communication, 23(2), 112-130. doi:10.1080/07393180600714489.

Steam (2016a). America's Army 3. Retrieved November 29, 2016, from http://store.steampowered. com/app/13140/.

Steam (2016b). Arma 2. Retrieved November 30, 2016, from http://store.steampowered.com/app/33900/.

Steam (2016c). Call of Duty 4: Modern Warfare. Retrieved November 28, 2016, from http://store.steampowered. com/app/7940/.

Steam (2016d). Spec Ops: The Line. Retrieved November 29, 2016, from http://store.steampowered. com/app/50300/.

SteamSpy (2016). About. Retrieved November 28, 2016, from http://steamspy.com/about.

Sundberg, R., Eck, K., \& Kreutz, J. (2012). Introducing the UCDP non-state conflict dataset. Journal of Peace Research, 49(2), 351-362. doi:10.1177/0022343311431598.

SuperData (2015). Digital games set to outsell retail during 2014 holiday season. Retrieved from https://www. superdataresearch.com/digital-games-set-outsell-retail/.

UCDP (2016a). Definitions Uppsala Conflict Data Program. Retrieved November 24, 2016, from http://www. pcr.uu.se/research/ucdp/definitions/.

UCDP (2016b). Uppsala Conflict Data Program Database. Retrieved November 30, 2016, from http://ucdp.uu. $\mathrm{se} /$.

Valve Corporation (2016). Browse steam your way: introducing steam tags, a powerful new way to shop for games. Retrieved November 28, 2016, from http://store.steampowered.com/tag/?

van Dreunen, J. (2016). PC trumps mobile, console in booming \$61bn digital games market. Retrieved from http://www.gamesindustry.biz/articles/2016-01-26-pc-trumps-mobile-console-in-booming-usd61bn-digitalgames-market.

Van Zwieten, M. (2011). Danger close: contesting ideologies and contemporary military conflict in first person shooters (p. 13). Utrecht. Retrieved from http://www.digra.org/wp-content/uploads/digitallibrary/11312.17439.pdf. 